\title{
Design of Delta Primary - Transposed zigzag Secondary (DTz) Transformer to Minimize Harmonic Currents on the Three-phase Electric Power Distribution System
}

\author{
Chairul Gagarin Irianto ${ }^{1}$, Rudy Setiabudy ${ }^{2}$, and Chairul Hudaya ${ }^{2}$ \\ ${ }^{1}$ Department of Electrical Engineering, Universitas Trisakti, Jakarta, Indonesia \\ ${ }^{2}$ Department of Electrical Engineering, Universitas Indonesia, Depok, West Java, Indonesia \\ chairul_irianto@trisakti.ac.id,rudy@ee.ui.ac.id, c.hudaya@ee.ui.ac.id
}

\begin{abstract}
The delta primary - transposed zigzag secondary (DTz) transformer has been designed and used to reduce the bad impacts of the harmonic in the distribution power system. The DTz transformer is constructed with delta connection in primary winding and the three transposed windings at the different core legs of secondary winding. The harmonic reduction method of the DTz transformer applies two basic principles. The first principle is to inhibit electromagnetic energy of the harmonic currents by cancelling the phase polarity on the secondary winding. The second is to insulate the remaining of the mmf induction from harmonic current loads and minimize to circulate in the delta windings on the primary side.

The triplen harmonics currents generated on the primary and secondary winding of DTz transformer are simulated in this paper. Both balanced and unbalanced loads of the three-phase distribution system are examined. The experiment shows that the total THD current in the secondary winding when balanced loads are applied is about $70.8 \%$, and in the primary side is $24.3 \%$. While for unbalanced loads, the average THD in secondary winding is $68.44 \%$ and in delta winding is $26.4 \%$. It means the DTz transformer has a filter-ability to reduce about 42 $46 \%$ THD for both balanced and unbalanced loads.

By comparing the computer simulation results and data measurements through experiment in the laboratory, it is proved that the use of the proposed DTz transformer is one of the methods to reduce harmonic currents and inhibit them to enter to the supply system.
\end{abstract}

Keywords: triplen harmonic currents, balanced and unbalanced loads, delta primary transposed zigzag secondary winding (DTz) transformer, non-linear loads

\section{Introduction}

As a consequence of the increasingly widespread use of electronic devices and equipments or other nonlinear loads that are generating harmonics, current waveform and source voltage becomes a non-sinusoidal waveform due to the distortion. Harmonic problems on the power distribution system are getting worst now since more than $50 \%$ of the generated power capacity mostly serves the single-phase nonlinear loads [1]. Harmonic is a common phenomenon on the distribution system. An excessive harmonic distortion causes to the electric quality problem. One of them is that the power transformer has no longer effective and efficient anymore to prevent the flow of zero sequence currents into the supply side. As the result, the triplen harmonic currents from the consumer side freely enter to supply side without any reduction by transformer [2].

Transformer is a main tool in electric power systems [3]. The recent transformer has now being developed and expected to be able to resolve the harmonic problem of the electric quality at the electric power supply. Steinmetz (1916) was the first researcher who proposed the transformer with a delta winding configuration in order to block the third harmonic currents due to saturation of transformers iron core and electric machineries [4]. Furthermore, it's known that the primary delta winding is able to force the triplen harmonic currents from non- 
linear loads circulated only in the primary delta of power transformer so it would not flow into the supply system [5]. But this causes huge power loss (represented by heat) in the transformer and decrease the transformer efficiency [5,6,7].

There are many considerable research literatures which discuss on transformer technology, especially for specific design to reduce the triplen harmonic currents such as Dy transformer, K-rated distribution transformer and Dz transformer. Although they have advantages, however, there are still limitations. The secondary windings of Dy transformer are not able to limit the triplen harmonic currents from the unbalanced non-linear loads. Consequently, the mmf induction from the triplen harmonic current loads enlarges the current circulation in the delta primary; thus, it creates the power losses and increases the temperature of the transformer $[7,8]$. Similar to Dy transformer, K-rated transformer is not able to limit the harmonics as well, but this transformer is designed to tolerate a high frequency of the harmonic currents [5]. Secondary Dz transformer has the advantages to limit the harmonics from balanced loads but its performance depends on the proximity of distance with the loads [9]. In addition, if the loads are unbalanced, the resultant of the mmf induction of the triplen harmonic currents cannot be reduced and still circulates in the primary delta side. As the result it increases the power loss and reduces the efficiency of transformer [7,9].

Table 1. Comparison between the Dy, Dz and DTz transformer

\begin{tabular}{|l|l|l|l|l|}
\hline No. & Items & Dy Transformer & Dz Transformer & Proposed DTz Transformer \\
\hline 1 & $\begin{array}{l}\text { Winding } \\
\text { configuration } \\
\text { and core-leg }\end{array}$ & $\begin{array}{l}\text { Has no ability to balance } \\
\text { the magnetic flux of each } \\
\text { load current phase. Each } \\
\text { core-leg is only passed by } \\
\text { one current load. }\end{array}$ & $\begin{array}{l}\text { Has an ability to balance the } \\
\text { some part of magnetic flux as } \\
\text { each core-leg is passed by two } \\
\text { curent loads. }\end{array}$ & $\begin{array}{l}\text { The inductive impedance of secondary } \\
\text { winding is balanced since each core-leg } \\
\text { is passed by three load currents. As the } \\
\text { result, the inductive volage in each is } \\
\text { much more symetric. }\end{array}$ \\
\hline 2 & $\begin{array}{l}\text { Current } \\
\text { circulation in } \\
\text { primary delta } \\
\text { winding }\end{array}$ & $\begin{array}{l}\text { The magnetic flux } \\
\text { produces the higher } \\
\text { induction voltage which } \\
\text { in turn letting the current } \\
\text { circulating in the primary } \\
\text { delta larger. }\end{array}$ & $\begin{array}{l}\text { The magnetic flux of the } \\
\text { triplen harmonic in the zigzag } \\
\text { secondary winding is small or } \\
\text { zero when it is on balanced } \\
\text { load. It comes to be larger } \\
\text { when it is installed unbalanced } \\
\text { load. }\end{array}$ & $\begin{array}{l}\text { The resultant of magnetic flux from } \\
\text { triplen harmonic has been minimized by } \\
\text { zigzag secondary winding. This } \\
\text { causes the primary winding losses } \\
\text { decreases. Other effect is that the triplen } \\
\text { harmonic current flowing to the } \\
\text { distribution system can be reduced. }\end{array}$ \\
\hline 3 & $\begin{array}{l}\text { Secondary } \\
\text { winding } \\
\text { impedance }\end{array}$ & Small compared to others & $\begin{array}{l}\text { Large enough compared to } \\
\text { others }\end{array}$ & $\begin{array}{l}\text { Larger than the Dy and Dz, } \\
\text { consequently the current flowing in the } \\
\text { winding is smaller and the winding } \\
\text { losses are decreasing. }\end{array}$ \\
\hline
\end{tabular}

This paper presents the results of the research and laboratory experiment concerning with the reduction of the triplen harmonic based on the principle of the phase polarity cancellation and circulation by developing a DTz transformer. The DTz transformer is constructed with delta connection in primary winding and the three transposed windings at the different core legs of secondary winding. The reduction method of the DTz transformer is based on two basic principles [10]. The first principle is to inhibit electromagnetic energy of the harmonic currents by cancelling the phase polarity on the secondary side, while the second is to insulate the remaining of the mmf induction from harmonic current loads as well as minimizing it to circulate in the delta windings on the primary side. Using some small capacity of the DTz transformers in the electric distribution system are one of the effective options as they are cheaper, energy-efficient and effective harmonic currents reduction. The summary comparison between the Dy, Dz and proposed DTz transformer can be seen in Table 1 above.

\section{Background and Case Model}

Harmonics current and voltage have been existing since the beginning of the history of the alternating current (AC) power system [4]. However, the type and quantity of the harmonicproducing power electronics have rapidly increased today. Because the power electronics have advantages in terms of efficiency and controllability; therefore, it can be used at the different 
power levels ranging from a low voltage domestic tool to a high voltage converter. This means that the harmonics become a serious problem on the electric distribution system.

The important thing in the harmonics problem is that the spectrum of the distortion frequency will be depending on the type of non-linear loads. In general, the single-phase nonlinear loads which are supplied by the power distribution system are computers, servers, and fluorescent lamps. Frequency spectrum of the most dominant harmonics generated from this type of non-linear loads is the triplen harmonic [15], as shown in Table 2.

Table 2. Nonlinear loads and generated harmonics

\begin{tabular}{|l|l|l|l|}
\hline \multirow{2}{*}{ Tools } & \multicolumn{3}{|c|}{ THD Current (\%) } \\
\cline { 2 - 4 } & $\mathbf{3}^{\text {rd }}$ & $\mathbf{5}^{\text {th }}$ & $\mathbf{7}^{\text {th }}$ \\
\hline PC or Mini computer & 78 & 44 & 17 \\
\hline Light fluorescent & 36 & 3 & - \\
\hline Computer room (server, computer etc) & 48 & - & 16 \\
\hline
\end{tabular}

Triplen harmonic currents have become a very important issue in the modern power systems. The use of fluorescent lamps, which is getting bigger and widely dispersed, has caused a distortion to the sinusoidal voltage and current waveform. Furthermore, the nonsinusoidal currents will interact with the impedance of the power system which in turn will increase the level of voltage distortion in the line and produce the resonance between the capacitor (if available) and supply impedance.

\subsection{DTz Transformer Model}

The basic idea of the $\mathrm{DTz}$ transformer winding configuration is taken from the transposition theory of the three-phase transmission line to overcome the asymmetric line inductance due to the magnetic geometric location in the transmission line [14]. The idea was then applied for the DTz winding on the secondary side of transformer. By distributing the secondary phase winding among the three core legs symmetrically, it is expected that the transformer is able to inhibit the electromagnetic energy flow of harmonics and increase windings impedance. In this regard, the first principle of harmonic reduction is done by dividing the secondary phase winding $N_{2}$ into three symmetrical parts $\left(N_{2} / 3\right)$, and then put each part $\left(N_{2} / 3\right)$ of the windings on the transposed three core legs, finally they are connected series, as shown in Figure 1.

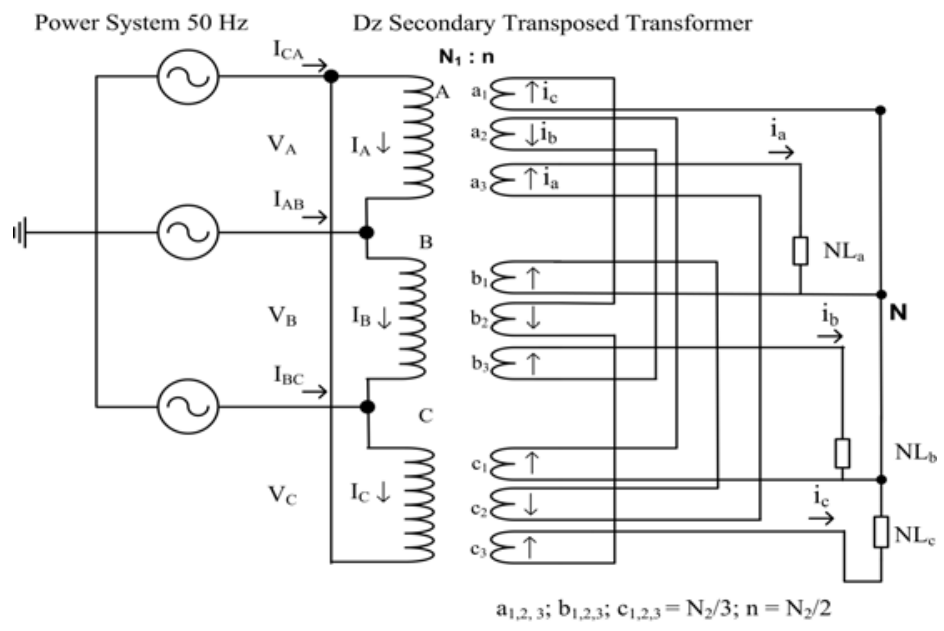

Figure 1. Configuration of DTz windings Transformer 
Figure 2 shows the proposed DTz transformer winding configuration to obtain $\mathrm{mmf}$ induction phasors relationship between the primary and secondary. While Figure 3 shows the physical proposed DTz transformer when measurement are conducted in the laboratory.

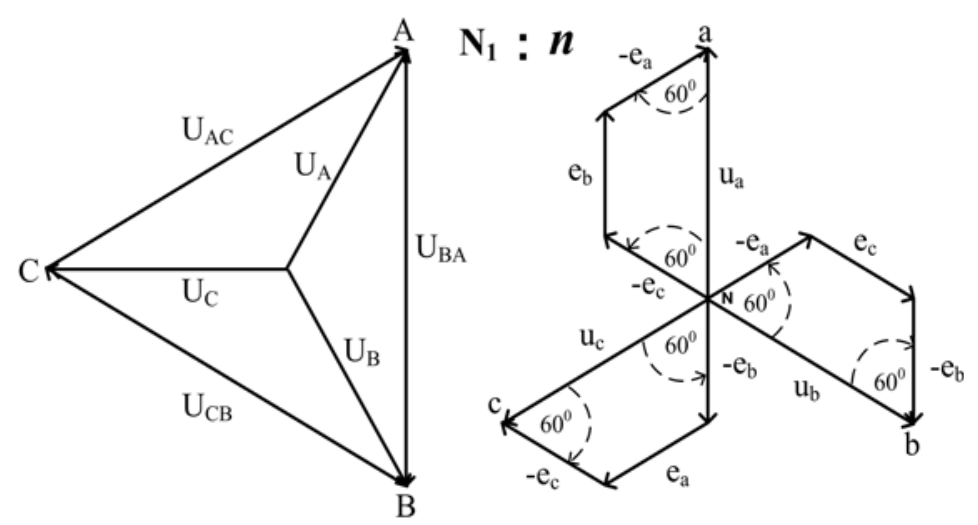

Figure 2. Primary and Secondary Phasor for Proposed DTz Transformer
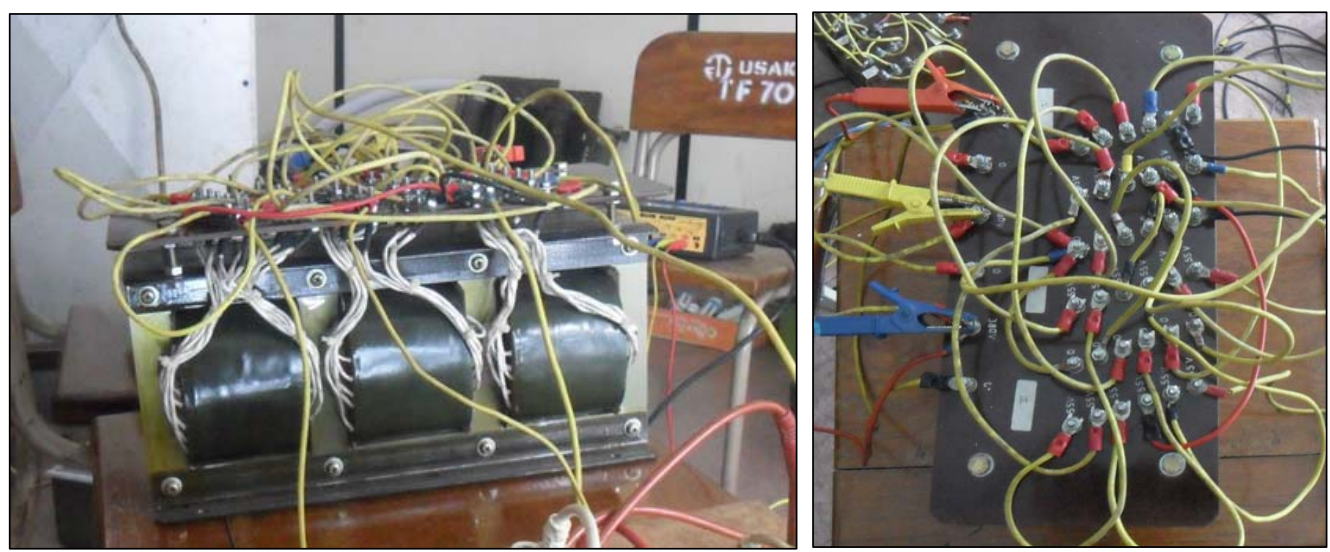

Figure 3. Proposed DTz Transformer on Laboratory Experiment

The phasors relationship of the primary and secondary voltage can be obtained by:

$$
\left[\begin{array}{l}
U_{A C} \\
U_{B A} \\
U_{C B}
\end{array}\right]=k_{1}\left[\begin{array}{l}
u_{a} \\
u_{b} \\
u_{c}
\end{array}\right]=k_{1}\left[\begin{array}{rrr}
-1 & 1 & -1 \\
-1 & -1 & 1 \\
1 & -1 & -1
\end{array}\right]\left[\begin{array}{l}
e_{a} \\
e_{b} \\
e_{c}
\end{array}\right]
$$

As shown in Figure 2, the vector diagram for each phase secondary voltage can be obtained by equation:

$$
u_{a}=\left(-e_{c}-e_{b}+e_{a}\right)
$$

For the balanced load condition,

$$
i_{a}=i_{b}=i_{c}=i \text {, }
$$

thus, the mmf phase winding is, 


$$
e_{a}=e_{b}=e_{c}=\left(\frac{N_{2}}{3}\right) \cdot i
$$

This value is equal to twice of the $1 / 3 \mathrm{mmf}$ windings, namely:

$$
u_{a}=e_{c} \cos 60^{\circ}+e_{b}+e_{a} \cos 60^{\circ}=2 e
$$

From equation (3), it can be determined the ratio of DTz secondary winding transformer which is $k_{1}=\left(N_{1} / n\right)$, where $n=\left(N_{2} / 2\right)$.

As reviewed, the DTz transformer is loaded by non-linear loads as shown in Figure 4. The diagram shows the first principle of the harmonic reduction, which is the reduction of mmf triplen harmonic on the same core legs in the phase windings. In other words, the resultant of the mmf induction of the triplen harmonic currents from the secondary windings is getting smaller.

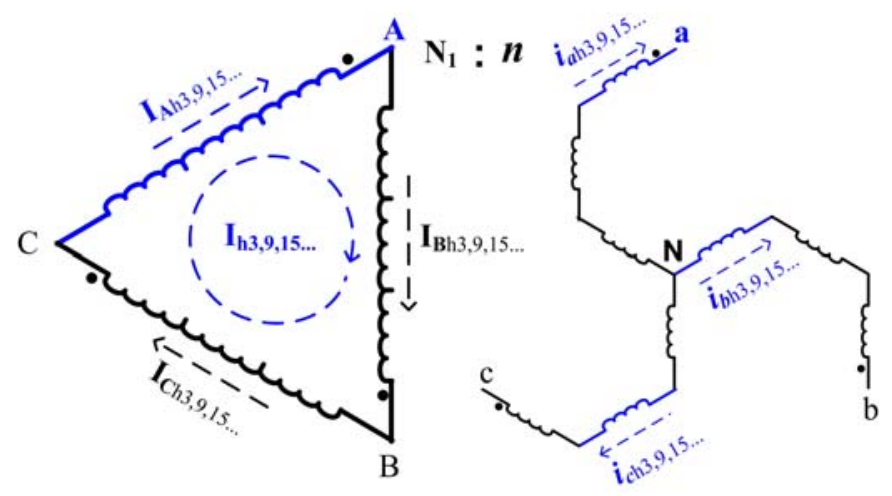

(a)

(b)

Figure 4. (a) Circulation of the triplen harmonic currents in the primary delta winding, (b) Reduction of the triplen harmonic currents at the secondary winding.

Figure 4(a) shows the relationship of the mmf vector of the secondary phase winding current which is formed by a zigzag winding connection. The harmonic currents in the zigzag winding, which is minimized in the delta winding, are:

$$
\left[\begin{array}{l}
i_{A} \\
i_{B} \\
i_{C}
\end{array}\right]=1 / k_{1}\left[\begin{array}{rrr}
-1 & -1 & 1 \\
1 & -1 & -1 \\
-1 & 1 & -1
\end{array}\right]\left[\begin{array}{l}
i_{a} \\
i_{b} \\
i_{c}
\end{array}\right]
$$

Figure 4(b) shows the polarity of current relationship in the secondary winding. The phase current -a, $i_{a}$ is the sum of the fundamental currents components, $i_{a 1}$ and the odd-order of the harmonic currents, $i_{a h}$. If the effective current, $I_{a r m s}=i_{a}$ then,

$$
i_{a}=I_{a 1}+\sum_{h=2 k+1}^{\infty} I_{a h}
$$


Where $k=1,2,3, .$. is the integer multiplication of the fundamental frequency. If it is assumed that the power supply is a three-phase source, the third harmonic components and its triplen will be in phase [8]. This condition can be stated as,

$$
I_{a 3,9,15 \ldots}=I_{b 3,9,15 \ldots}=I_{c 3,9,15 \ldots}=I_{h 3,9,15 \ldots} \angle 3 \times 0^{0}=I_{a 3} \angle 0^{0}
$$

Figure 4 (a) shows the second principle that is as an insulator in which connecting the primary winding $N_{1}$ in the delta configuration. This condition causes the flow of harmonic currents is insulated or forced to circulate only in the primary delta winding so it will not flow and distort the sinusoidal waveform of the current and voltage at the power supply side. The formula shows that the magnitude of the triplen frequency decreases to one third of the harmonic currents in the primary side when using balanced loads. For example, the current circulation in A-phase windings on the primary A-leg core;

$$
I_{A h 3,9,15, . . .}=\frac{n}{N_{1}}\left(-i_{c h 3,9,15, . .} / 3+i_{b h 3,9,15, . .} / 3-i_{a h 3,9,15, . .} / 3\right)
$$

This yields,

$$
i_{A h 3,9,15, . .}=\frac{n}{3 N_{1}} I_{a h 3,9,15, . .} \angle 0^{0}
$$

Equation (8) describes the remaining harmonic current which is induced to the primary delta windings through the core is becoming smaller. This will therefore minimize the loss of the harmonic current circulation.

Besides having capabilities to reduce the triplen harmonics by cancelling phase polarity and circulation, the additional advantage of the DTz winding transformer is much more efficient as it can reduce the transformer loss. This advantage is obtained by increasing the resistive impedance of the transformer windings.

Figure 4 and equation (9) inform that to produce an effective output voltage $V_{2}$, the need of the mmf induction of the secondary DTz transformer is larger than that of the Dy transformer and conventional secondary Dz [13]. The mmf induction ratio in secondary winding of Dy, Dz and DTz transformer is $1: 1.33: 1.55$, as shown in Figure 5.c1, 5.c2 and 5.c3, respectively.

In other words, to produce an effective output voltage $V_{2}$ the DTz transformer needs a mmf of 1.55 times much bigger than that of Dy transformer. With the same condition, DTz requires about 1.16 times much bigger than that of the conventional transformers Dz. When $\mathrm{mmf}$ induction is high, the inductive impedance value becomes higher as well. As the result, the electromagnetic energy of the triplen harmonics can be resisted to enter the supply system [12]. In addition, based on Ohm's law,

$$
V=I R
$$

Where:

$\mathrm{V}$ is the effective output voltage $V_{2}$ [Volt]; I is current [Ampere], and $\mathrm{R}$ is the resistive impedance of windings [Ohm].

And, based on the equation of power loss of transformer windings :

$$
P_{\text {loss }}=I^{2} R=\left(\frac{V_{2}}{R}\right)^{2} R
$$




$$
P_{\text {loss }} \approx(1 / R)
$$

Where

$P_{\text {loss }}$ is the power loss in the transformer windings (Watt).

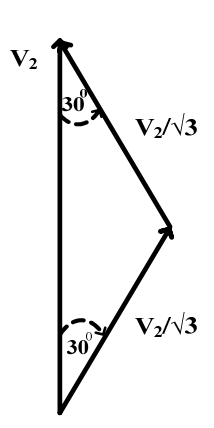

(a)

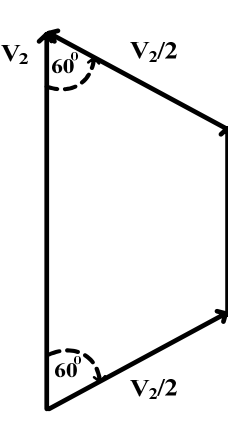

(b)

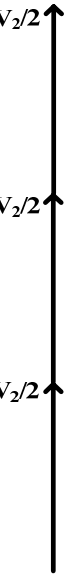

(c1) (c2)

(c3)

(c)

Figure 5. Secondary side of voltage phasor $V_{2}$ (a). Dz transformer, (b). DTz transformer; and

(c) The resultant of voltage vector $V_{2}$ on transformer (c1) Dy, (c2) Dz and (c3) DTz.

This shows that the impedance values of DTz windings is bigger than that of other transformers as shown in Figure 6. As the power and resistive impedance is linear, thus, a change in resistive impedance has a proportional relation to the power loss. This means, for the same input of the power capacity, the efficiency of the DTz transformer will be higher.

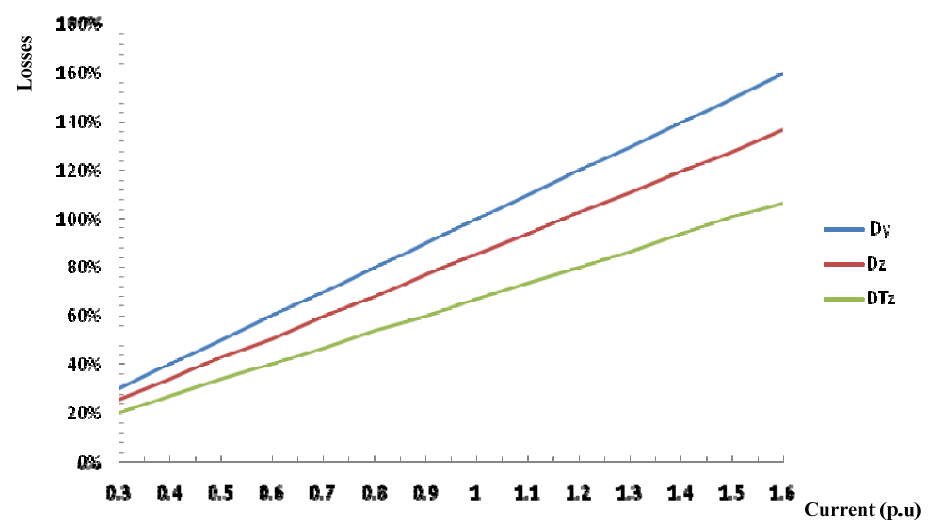

Figure 6. The ratio of output currents and power loss of the Dy, DZ and DTz transformer windings.

\subsection{Simulation Model of DTz Transformer}

The objective of the research is to investigate the ability of the DTz transformer to reduce the harmonics currents in accordance to the primary side or supply/utility. To study the characteristics of this transformer, the power supply systems, DTz transformers and nonlinear loads have been developed. A power system is made up in a $380 \mathrm{~V}$ ideal sinusoidal voltage 
source model. In this case, the impedance and harmonic voltage of the power systems are neglected. The proposed DTz transformer has rating: 1,250 VA; $50 \mathrm{~Hz} ; 380 \mathrm{~V}$ of primary voltage and $220 \mathrm{~V}$ of secondary voltage.

\subsubsection{Balanced Loads}

When using the balanced loads, the DTz transformer was loaded by 330 VA each phase. Under the simulation, it is expected that these non-linear loads generated a THD for more than $70 \%$ to the secondary terminal of a three-phase-four-wire DTz.

The Fourier method is then applied to analysis the distorted current waveform at the secondary winding as shown in Figure 7(a) and at the primary as shown in Figure 7(b). The trigonometric of Fourier series can be described as,

$$
f(t)=A_{0}+\sum_{n=1}^{\infty} A_{n} \cos \left(n \omega_{0} t+\theta_{0}\right)
$$

Where:

$$
\begin{aligned}
& A_{0}=\frac{1}{2} \omega_{0} ; \\
& A_{n}=\left(a_{n}^{2}+b_{n}^{2}\right)^{1 / 2} \text {; and } \theta_{n}=\arctan \left(-\frac{b_{n}}{a_{n}}\right)
\end{aligned}
$$

Where the coefficient $A_{0}$ is a fundamental current component, $A_{n}$ is the magnitude and $\theta_{n}$ is the phase angle of the-n harmonic component. Figure 7 shows the simulation of current waveform in the secondary and delta winding.

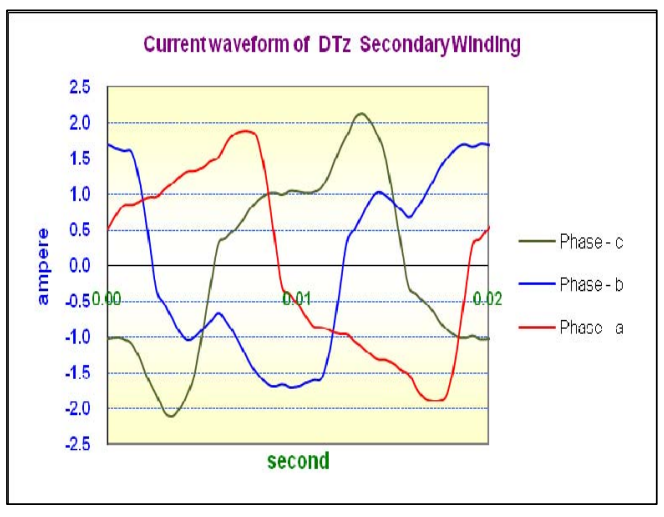

(a)

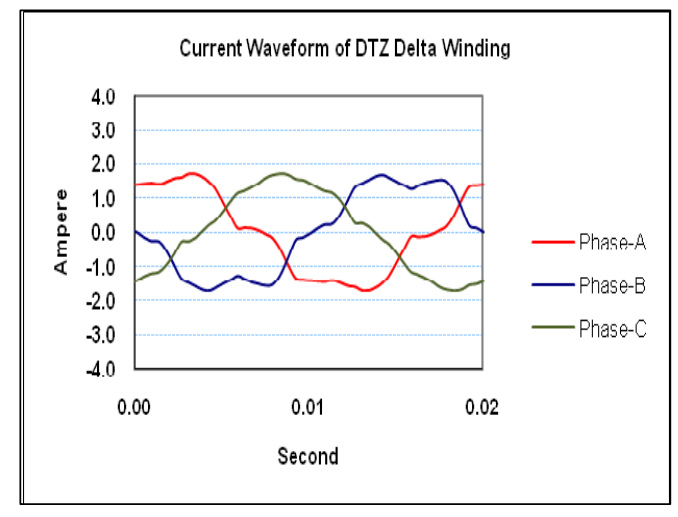

(b)

Figure 7. The distorted current waveform on balanced loads

(a) phase-a-b-c (secondary winding), (b) phase-A-B-C (delta winding)

\subsubsection{Unbalanced Loads}

The simulation was then carried out to examine the unbalanced loads. For this purpose, the simulation is conditioned with the balance factor of $30 \%$, thus, phase-a, phase-b, and phase-c was loaded by $390 \mathrm{VA}, 300 \mathrm{VA}$, and $210 \mathrm{VA}$, respectively. 
Figure 8(a) shows the distorted harmonic current in the secondary winding for phase a-b-c, while Figure $8(\mathrm{~b})$ shows that in the phase A-B-C in primary winding.

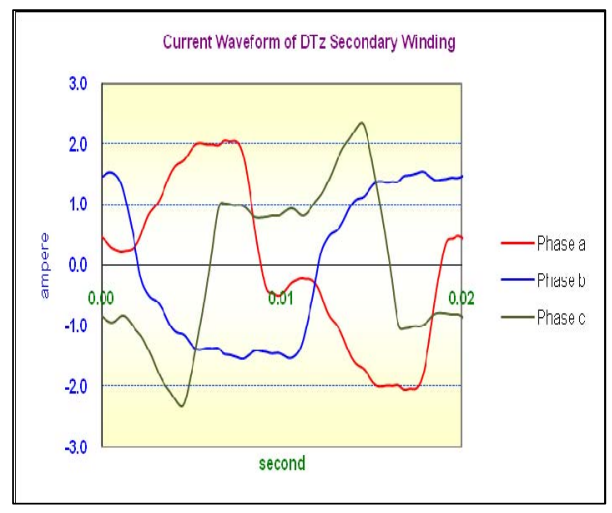

(a)

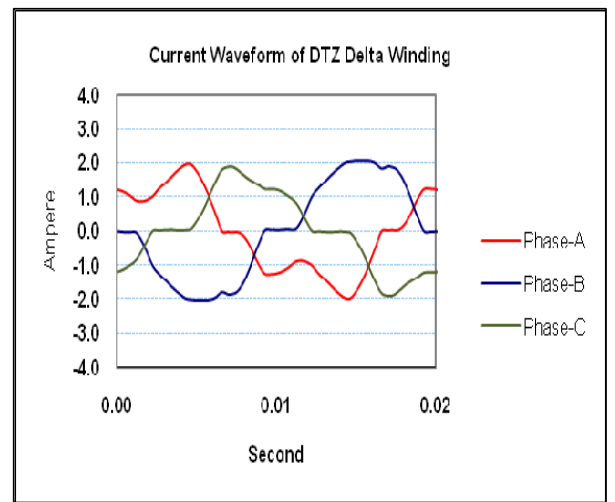

(b)

Figure 8. The distorted current waveform on unbalanced loads (a) phase-a-b-c (secondary winding), (b) phase-A-B-C (delta winding)

\section{Laboratory Experiment}

Laboratory experiments were carried out to examine the computer simulation as explained in previous section. For the purpose of generating harmonic currents, some non-linear loads such as fluorescent lamp, compact fluorescent lamp (CFL) are used. The proposed DTz transformer with the same rating is designed. Both balanced (330 VA each phase) and unbalanced loads (390 VA, 300 VA and 210 VA) are exercised by a power quality and energy analyzer.

\subsection{Case 1: Balanced Load}

Figure 9 shows the current waveform for the balanced loads in the secondary and delta winding.
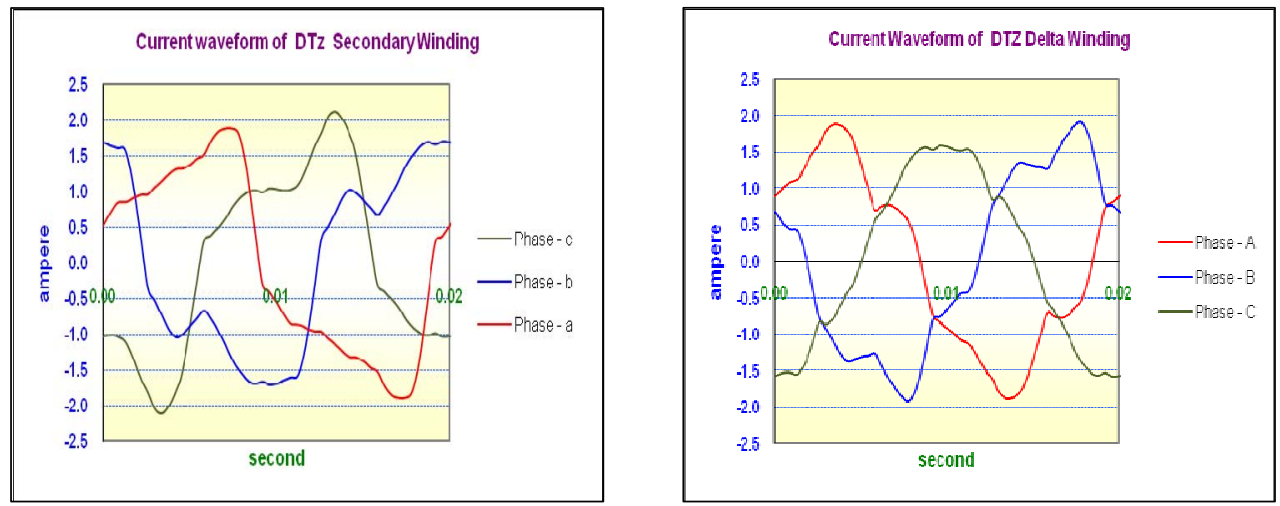

Figure 9. Current Waveform of Balanced Loads

(a) The Secondary Winding (b) The Delta Winding

While Figure 10 shows the spectrum of harmonic current when the transformer was loaded by balanced loads. 


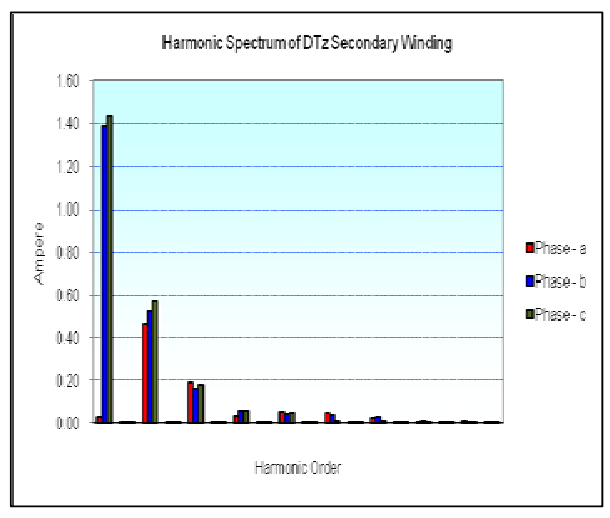

(a)

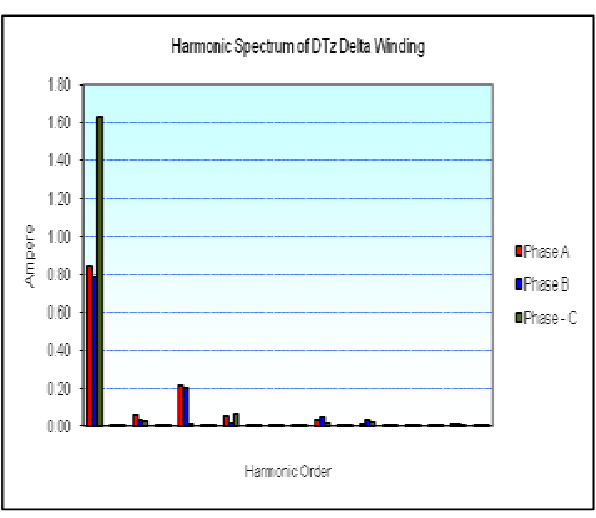

(b)

Figure 10. Spectrum of Harmonic Currents for Balanced Loads

(a) The Secondary Winding (b) The Delta Winding

As shown in Figure 10(a), the third and its triplen harmonic currents inject about $70.8 \%$ to the secondary winding. Although the amount is small, the $5^{\text {th }}, 7^{\text {th }}, 11^{\text {th }}, 13^{\text {th }}$, and $17^{\text {th }}$ also contribute to harmonic currents. While for primary winding, Figure 10(b) informs that the proposed DTz transformer has a filtering ability to reduce the third and its triplen harmonic currents. It can be seen by a decreasing THD current primary winding to be $24.3 \%$.

\subsection{Case 2: Unbalance Load}

An unbalance factor of $30 \%$ was applied in the experiment. Figure 11 shows the current waveform when the DTz transformer was loaded by a 390 VA, 300 VA and 210 VA each phase.

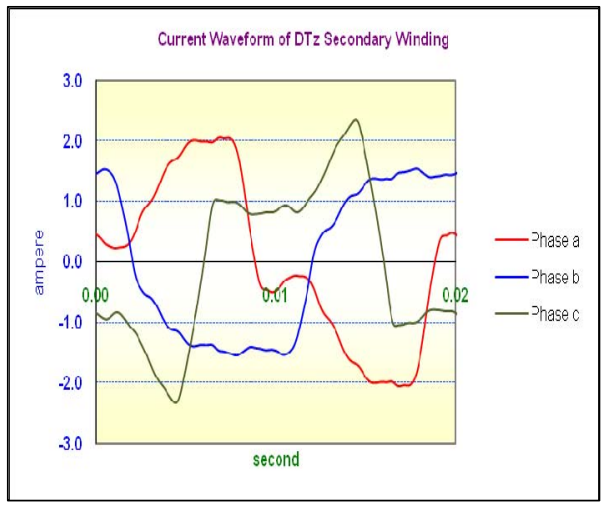

(a)

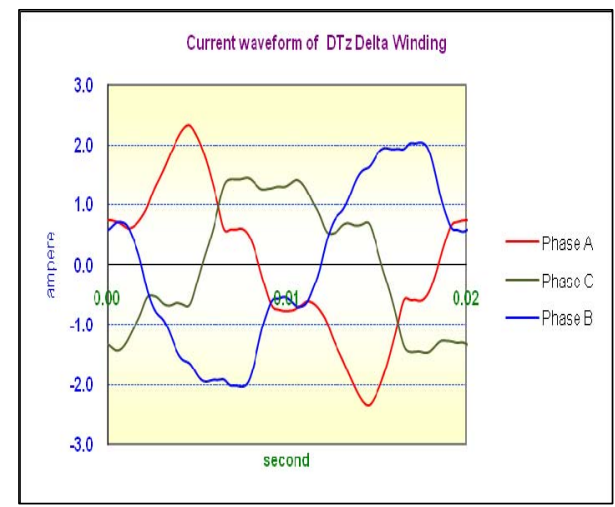

(b)

Figure 11. Current Waveform of unbalanced Loads (a) The Secondary Winding (b) The Delta Winding

Figure 12(a) shows that the third and its triplen harmonic currents magnitude contribute to the largest value of THD current, which is $68.44 \%$. In addition, the $5^{\text {th }}, 7^{\text {th }}$, and $11^{\text {th }}$ also gave to the THD level, although the amount was not significant.

The decrease of the third and its triplen harmonic current is shown in Figure 12(b). The THD current can be reduced from $68 \%$ in the secondary side to $26.4 \%$ in the delta winding. 


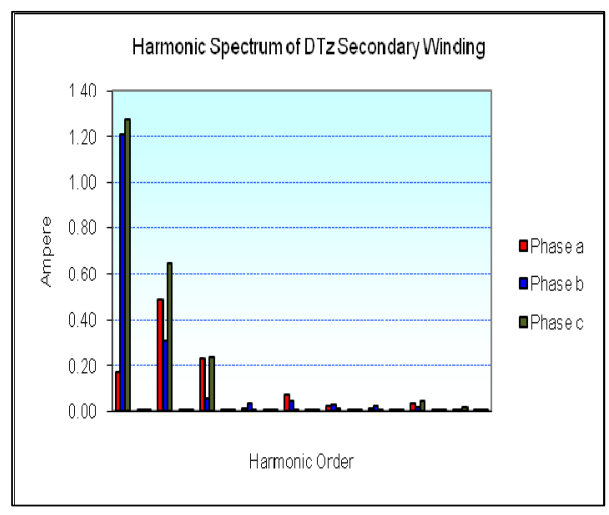

(a)

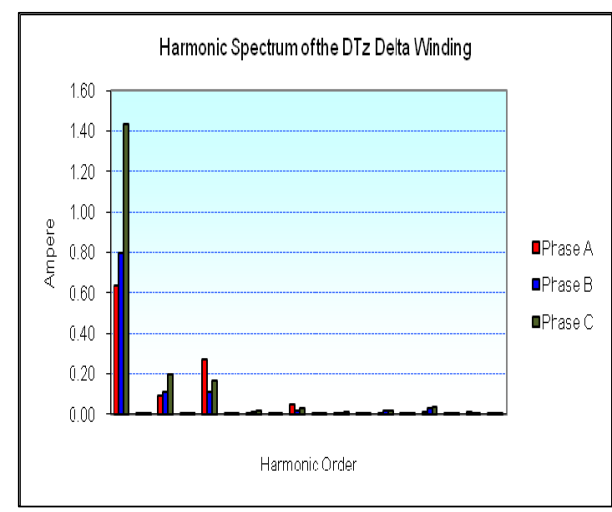

(b)

Figure 12. Spectrum of Harmonic Currents for Balanced Loads

(a) The secondary side and (b) The Delta Winding

\section{Detail Comparison of Simulation and Experiment}

The comparison between the laboratory experiment and computer simulation is given in Table 3 below.

Table 3. THD current (\%) of Balanced and Unbalanced Loads

\begin{tabular}{|c|c|c|c|c|c|c|}
\hline \multirow{2}{*}{ ITEM } & \multicolumn{2}{|c|}{$\begin{array}{l}\text { Balanced Load by } \\
\text { Lab Experiment }\end{array}$} & \multirow{2}{*}{\begin{tabular}{|c|} 
Balanced \\
Load by \\
Computer \\
Simulation \\
Primary
\end{tabular}} & \multicolumn{2}{|c|}{$\begin{array}{l}\text { Unbalanced Load by } \\
\text { Lab Experiment }\end{array}$} & \multirow{2}{*}{ 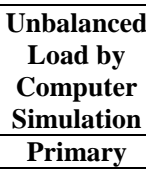 } \\
\hline & Secondary & Primary & & Secondary & Primary & \\
\hline $\begin{array}{l}\text { THD Current } \\
\text { Average (\%) }\end{array}$ & 70.8 & 24,3 & 24,85 & 68.44 & 26,4 & 27,6 \\
\hline
\end{tabular}

Table 3 indicates the summary comparison between the simulation and actual data of laboratory experiment of the DTz transformer. By comparing the simulation results with measurement data, it can be seen that the error or difference between those is about $0.02 \%$ for balanced loads and $4 \%$ for unbalanced loads. This small error confims the correctness and accuracy of the model and experiment.

\section{Conclusion}

The delta - transposed zigzag secondary winding (DTz) transformer has been proposed to minimize the third and its triplen harmonic currents on the three-phase electric power distribution system. A 1,250 VA DTz model has been designed. Both computer simulation and laboratory experiments show that the DTz transformer has double abilities to inhibit the harmonic both electrically or magnetically by increasing the impedance transformer and balancing the mmf inductions in the core. The DTz transformer winding configuration can reduce the harmonic currents and the rms currents of the primary phase. This is a best practice that can be applied for the power transformers in the distribution system which generally has many non-linear loads that are installed unbalance.

The experiment shows that the total THD current in the secondary winding when balanced loads are applied is about $70.8 \%$, and in the primary side is $24.3 \%$. While for unbalanced loads, the average THD in secondary winding is $68.44 \%$ and in delta winding is $26.4 \%$. It means the DTz transformer has a filter-ability to reduce about 42 - $46 \%$ THD for both balanced and unbalanced loads. By installing a number of small DTz transformers in the 
distribution systems, the overall system performance will be improved and the power quality problems due to harmonics can be eliminated.

\section{References}

[1] Ewald F. Fuch, Mohammad A. S. Masoum, "Power Quality in Power Systems and Electrical Machines”, Elsevier, 2008.

[2] Tongxin Zheng, Elham B. Makram, and Adly A. Girgis, "Evaluating Power System Unbalance in the Presence of Harmonic Distortion", IEEE Transactions On Power Delivery, Vol. 18, No. 2, April 2003.

[3] Asaad A. Elmoudi, "Evaluation of Power System Harmonic Effects on Transformers Hot Spot Calculation and Loss of Life Estimation”, Doctoral Dissertation, Department of Electrical and Communications Engineering Power Systems and High Voltage Engineering, Helsinki University of Technology, Espoo 2006.

[4] Grady, WM, Santoso, Surya. "Understanding Power System Harmonics”, September, 22, 2002.

[5] Azhar Ahmad, Rosli Omar and Marizan Sulaiman, "Application of ZigZag Transformers to Mitigate Triplen Harmonics in 3 Phase 4 Wire Electrical Distribution System”, $4^{\text {th }}$ Student Conference on Research and Development (SCOReD 2006), Shah Alam, Selangor, MALAYSIA, 27-28 June, 2006.

[6] Sy-Ruen Huang, Bing-Nan Chen, "Harmonic Study of Le Blanc Transformer for Taiwan Railway's Electrification System”, IEEE Transactions on Power Delivery, Vol.17 No.2 April 2002.

[7] J. Schonek, Cahier technique no. 202 the singularities of the third Harmonic, Schneider Electric, http://www.schneider-electric.com, ECT 202(e) first issued February 2001.

[8] Leon M. Tolbert, Harold D. Hollis, Peyton S. Hale, Jr.”Evaluation of Harmonic Suppresion Devices” IEEE IAS Annual Meeting, Oct. 6-10, 1996, San Diego, CA, pp. 2340-2346.

[9] Bhim Singh, P. Jayaprakash, T. R. Somayajulu, and D. P. Kothari, "Reduced Rating VSC With a Zig-Zag Transformer for Current Compensation in a Three-Phase Four-Wire Distribution System”, IEEE Transactions On Power Delivery, Vol. 24, No. 1, January 2009.

[10] Chairul Gagarin Irianto, Rudy Setiabudy, "Performance Analysis of Delta-zigzag (Dz) Connection Transformer With Secondary symmetrical Cross-winding Minimized Harmonics Based on the Rating of Volt-Ampere Output Power”, Proceeding of the $11^{\text {th }}$ International Conference on QiR (Quality in Research) Faculty of Engineering, University of Indonesia, Depok, Indonesia, 3-6 August 2009 ISSN 114-1284.

[11] Deng Ming-li, et al, "The simulation analysis of harmonics and Negative sequence with Scott wiring transformer”, 2008 International Conference on Condition Monitoring and Diagnosis, Beijing, China, April 21-24, 2008.

[12] PLITRON, Narrow Bandwidth Technology A PLITRON White Paper, PLITRON Manufacturing Inc. \#8-601 Magnetic Drive, Toronto, Ontario M3J 3J2 Canada, www.plitron.com, May 8, 2002

[13] M. Kostenko, L. Piotrovsky, Electrical Machines Vol. I Direct Current Machines And Transformer, MIR Publishers, Moscow 1968.

[14] TS Hutauruk, Analisa Sistem Tenaga, Erlangga

[15] Technical Bulletin 1-11, MGE Dual Zigzag Harmonic Reduction Transformers 


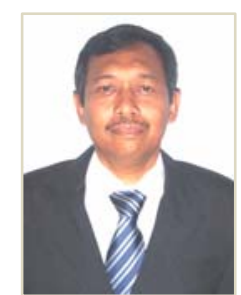

Chairul Gagarin Irianto was born in Surabaya, Indonesia in 1961. He received B.Sc degree in Electrical Engineering from Faculty of Industrial Technology, University of Trisakti, Indonesia in 1986 and MS degree in Electrical Engineering from Bandung Institute of Technology, Indonesia in 1992. He is currently a Doctor candidate in Department of Electrical Engineering, Universitas Indonesia. He has been joining with the Department of Electrical Engineering, University of Trisakti since 1987 just one year after his graduation. Mr. Gagarin has published several papers in national and international journal and conferences in the field of power engineering. During 2007-2010 he was a head of department of electrical engineering, University of Trisakti.

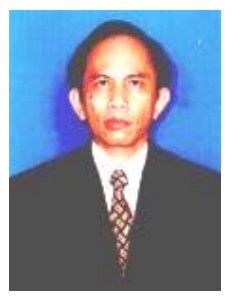

Rudy Setiabudy earned his bachelor degree from the Department of Electrical Engineering Universitas Indonesia in 1982. On October 1985 he honored a scholarship from the Government of Indonesia to continue his education to France. He received his master degree from Institute National Polytechnique de Grenoble (ENSIEG/INPG) in 1987 and doctoral degree from L'University de Montpellier II, France in 1991. Since 1991 he has been delivering lecture on Electric Materials Engineering and Electric Measurement Engineering at the Department of Electrical Engineering, Universitas Indonesia. During 1993 - 1998 he was a head of Electric Measurement Laboratory and from 1997 - 2004 he served as head of Department of Electrical Engineering, Universitas Indonesia. Dr. Rudy has published several papers in the national and international journal and attended seminar in national and international level.

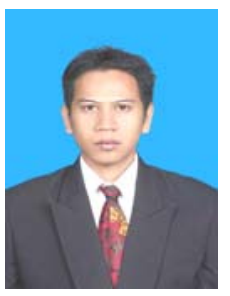

Chairul Hudaya was born in 1984 in Lampung Province, Indonesia. He received his bachelor and master degree from the Department of Electrical Engineering Universitas Indonesia and Department of Energy System Engineering, Seoul National University in 2006 and 2009 respectively. From August 2009, he has been working for the Department of Electrical Engineering, Universitas Indonesia as a lecturer. The subjects he teachs are Wave \& Optic Physics and Mechanic \& Heat Physics in the International Program and Electric Circuit Analysis and Electric Material Engineering in the Regular Program. Mr. Hudaya's research interest includes renewable energy generation, power quality and nuclear reactor safety. He has published several papers in the national and international conferences covering two fields i.e. power engineering and nuclear engineering. Currently he has received several grants from the governments, state-owned and private companies to conduct research in the field of energy and electricity. 